\title{
Impact of inflammation and immunotherapy in renal cell carcinoma (Review)
}

\author{
JIAN SHI $^{1,2^{*}}$, KESHAN WANG $^{1,2^{*}}$, ZHIYONG XIONG ${ }^{1,2^{*}}$, CHANGFEI YUAN $^{1,2}$, CHENG WANG $^{1,2}$, \\ QI CAO ${ }^{1,2}$, HUANG YU ${ }^{1,2}$, XIANGUI MENG ${ }^{1,2}$, KAIRU XIE ${ }^{3}$, ZHIXIAN CHENG $^{1,2}$, \\ $\mathrm{HONGMEI} \mathrm{YANG}^{3}, \mathrm{KE} \mathrm{CHEN}^{1,2}$ and XIAOPING $\mathrm{ZHANG}^{1,2}$ \\ ${ }^{1}$ Department of Urology; ${ }^{2}$ Institute of Urology, Union Hospital, Tongji Medical College, \\ Huazhong University of Science and Technology, Wuhan, Hubei 430022; \\ ${ }^{3}$ Department of Pathogenic Biology, School of Basic Medicine, \\ Huazhong University of Science and Technology, Wuhan, Hubei 430030, P.R. China
}

Received January 9, 2020; Accepted July 23, 2020

DOI: $10.3892 / \mathrm{ol} .2020 .12135$

\begin{abstract}
Substantial research attention has been directed at exploring the mechanisms and treatment of renal cell carcinoma (RCC). Indeed, the association between inflammation and tumor phenotypes has been at the center of cancer research. Concomitant with research on the inflammation response and inflammatory molecules involved in RCC, new breakthroughs have emerged. A large body of knowledge now shows that treatments targeting inflammation and immunity in RCC provide substantial clinical benefits. Adequate analysis and a better understanding of the mechanisms of inflammatory factors in the occurrence and progression of RCC are highly desirable. Currently, numerous RCC treatments targeted at inflammation and immunotherapy are available. The current review describes in detail the link between inflammation and RCC.
\end{abstract}

\section{Contents}

1. Introduction

2. Close association of inflammation with the occurrence and development of cancer

3. Role and mechanism of inflammation in the development of RCC

4. Important inflammation-related pathways in the

Correspondence to: Professor $\mathrm{Ke}$ Chen or Professor Xiaoping Zhang, Department of Urology, Union Hospital, Tongji Medical College, Huazhong University of Science and Technology, 1277 Jie Fang Avenue, Wuhan, Hubei 430022, P.R. China

E-mail: shenke@hust.edu.cn

E-mail: xzhang@hust.edu.cn

${ }^{*}$ Contributed equally

Key words: renal cell carcinoma, inflammation-related pathway, inflammatory factor, immunotherapy, tumor microenvironment development of RCC

5. Role of inflammation factors and immune-related cells in the occurrence and progression of RCC

6. Inflammation-associated molecules and clinical prognosis in patients with $\mathrm{RCC}$

7. Anti-inflammatory immunotherapy in RCC

8. Conclusions and prospects

\section{Introduction}

Renal cell carcinoma (RCC) originates from the renal parenchyma and is the most common subtype of kidney cancer (1). According to 2018 GLOBOCAN data, RCC accounts for up to $2.4 \%$ of all cancer cases, with an estimated 338,000 patients diagnosed globally each year (2). It has been shown that $25-30 \%$ of affected patients have metastatic disease and therefore poor survival outcomes (3). Surgery remains the most effective treatment for both localized and locally advanced $\mathrm{RCC}$, with those patients with RCC who receive surgical excision showing a good prognosis. However, the total recurrence rate after surgical resection is high, estimated at $35 \%$ (4).

Although there is now a greater understanding of the occurrence and development of RCC based on previous research, the clinical prognosis of patients with regard to the biological behavioral characteristics of RCC is still unsatisfactory. In recent years, the association between inflammation and tumors has become the focus of cancer research. Inflammation is a fundamental innate immune response to perturbed tissue homeostasis (5). Numerous studies have shown that inflammatory molecules and pathways play an important role in the development of cancer, such as breast cancer, pancreatic cancer, colorectal cancer, colon cancer, rectal cancer, prostate cancer, bladder cancer, lung cancer and ovarian cancer (6-8). Inflammation is highly associated with RCC, and participates in the development of RCC tumors, which are considered to be immunogenic $(9,10)$. The present review summarizes the main inflammatory response features in RCC, focusing primarily on immune-related molecules and immunotherapy to elucidate the association between inflammation and $\mathrm{RCC}$, and its role in the treatment of RCC. 


\section{Close association of inflammation with the occurrence and development of cancer}

Inflammation is considered a hallmark of cancer development. It is estimated that potential infections and inflammatory responses contribute to $15-20 \%$ of cancer-associated deaths globally (11). Evidence shows that the inflammatory response plays a vital role in the occurrence and development of tumors (12). Inflammatory bodies, cytokines, chemokines, transcription factors and immune cells drive the inflammatory tumor microenvironment (TME) through multiple inflammation-associated pathways. It is now increasingly being recognized that inflammation is inextricably linked to cancer $(5,13,14)$. Growth factors alter endocytosis and receptor cycling in cancer cells through several pathways, inhibition of negative feedback mechanisms that attenuate growth and enhancement of receptor-like tyrosine kinases to enrich proliferation-related downstream signaling (15). These changes increase genetic mutations and anti-apoptotic signaling, and promote angiogenesis, thereby promoting cancer progression $(6,16,17)$.

\section{Role and mechanism of inflammation in the development of RCC}

Inflammation is the natural defense mechanism of the body against microbial infection and other noxious stimuli, which inevitably cause tissue damage. Inflammatory cells accumulate at the site of injury, secrete a large amount of inflammatory mediators, promote tissue breakdown and enhance the defense of the host against potential pathogens $(18,19)$. Inflammation is divided into acute inflammation and chronic inflammation. Acute inflammation contributes to cancer regression $(7,20)$, whereas chronic inflammation promotes cancer progression (21). Currently, details regarding the pathogenesis of cancer arising from inflammation are accumulating at an exponential rate. There are two different modes for the association between inflammation and cancer, namely the intrinsic and extrinsic pathways (22). DNA damage, chromosomal instability and epigenetic changes lead to aberrant gene expression, which is a key feature of intrinsic pathways. Inflammatory signals caused by infections and autoimmune diseases are associated with extrinsic pathways. A variety of important transcription factors, including nuclear factor- $\kappa \mathrm{B}(\mathrm{NF}-\kappa \mathrm{B})$ and signal transducer and activator of transcription 3 (STAT3) are activated in these two pathways and drive the inflammatory cascade $(23,24)$.

\section{Important inflammation-related pathways in the development of RCC}

Inflammation and RCC are closely associated, and numerous inflammatory pathways interact with RCC. Four of these pathways that are particularly important include the Von Hippel-Lindau (VHL), mechanistic target of rapamycin (mTOR), tumor necrosis factor (TNF) and STAT pathways.

VHL pathway. VHL is a gene that suppresses the development of RCC and has the highest mutation rate among other genes involved in $\operatorname{RCC}(25,26)$. The main function of
VHL is to control the oxygen-sensing mechanism of cells by regulating the hypoxia-inducible factor (HIF) $\alpha$ subunits $(-1 \alpha,-2 \alpha$ and $-3 \alpha)(27-29)$. HIF is a heterodimeric transcription factor composed of two subunits, HIF- $\alpha$ and HIF- $\beta$ (30). Although the $\beta$-subunit of HIF is constitutively expressed, HIF- $\alpha$ protein is only expressed under hypoxic conditions and when VHL is inactivated (31). VHL promotes the degradation of HIF- $\alpha$ under normoxic conditions to keep the HIF- $\alpha$ subunit level low (32). Under hypoxic conditions, VHL is inactivated, leading to the accumulation of HIF- $\alpha$, which binds to HIF- $\beta$ and forms heterodimers that activate target genes. Therefore, the inactivation of VHL in RCC results in the upregulation of HIF- $\alpha$ isoforms, hence an increase in HIF, thereby activating the downstream carcinogenesis-related genes such as those associated with angiogenesis [vascular endothelial growth factor A (VEGFA) and platelet-derived growth factor $\beta$ (PDGF- $\beta$ )], erythropoiesis (erythropoietin) and glycolysis (solute carrier family 2 member 1 ). This causes tumor development processes such as cell growth, survival (cyclin G2 and transforming growth factor- $\alpha$ are increased) and migration [C-X-C motif chemokine receptor 4 (CXCR4) is increased] to be enhanced (33-35).

mTOR pathway. mTOR is a member of the protein kinase phosphatidylinositol 3-kinase (PI3K)-associated kinase family, which plays a key role in cell growth, cell proliferation, cell motility, cell survival, protein synthesis, autophagy and transcription (36). mTOR is composed of two complexes, mTOR complex 1 (mTORC1) and mTORC2, containing two different scaffolding proteins $(37,38)$. mTORC1 can be activated by growth factors and amino acids to promote cell growth (e.g., increases in cell size and mass) and cell proliferation. Activation of mTORC2 contributes to the regulation of cell polarity and the actin cytoskeleton $(39,40)$. mTOR is closely associated with the incidence of RCC.AKT, a molecule with an important role in the mTOR pathway, can be activated by inflammation, which causes tumorigenesis through mTOR signal transduction (41). Mutations in associated genes and inflammation lead to an increase in the incidence of metastatic RCC after an increase in mTOR activity (Fig. 1). Functional deletion mutations of the mTOR negative regulator PTEN, via the PI3K/AKT pathway, occur in $\sim 5 \%$ of patients with RCC $(42,43)$. Furthermore, the increased constitutive activity of mTORC1 promotes the proliferation and invasiveness of metastatic RCC (44). This is since the increased activity of mTORC1 promotes cell growth and proliferation (45). In addition, mTORC 1 increases the level of HIF-1 $\alpha$ in cells, thereby activating the production of proangiogenic factors such as VEGF, PDGF- $\alpha$ and TNF- $\alpha$ (46). In certain patients with RCC, activation of mTORC1 is mediated by a phosphatase PTEN loss-of-function mutation, which negatively regulates mTORC1 via the upstream PI3K/AKT pathway (47). Additionally, the occurrence of RCC in patients with tuberous sclerosis is due to mutations in tuberous sclerosis complex interfering with its negative regulation of mTORC1 activity $(48,49)$.

TNF pathway. TNF is a multifunctional pro-inflammatory cytokine secreted by macrophages and is the core driver of inflammatory responses (50). TNF binds and functions through its two different receptors, TNF receptor 1 (TNFR1) 


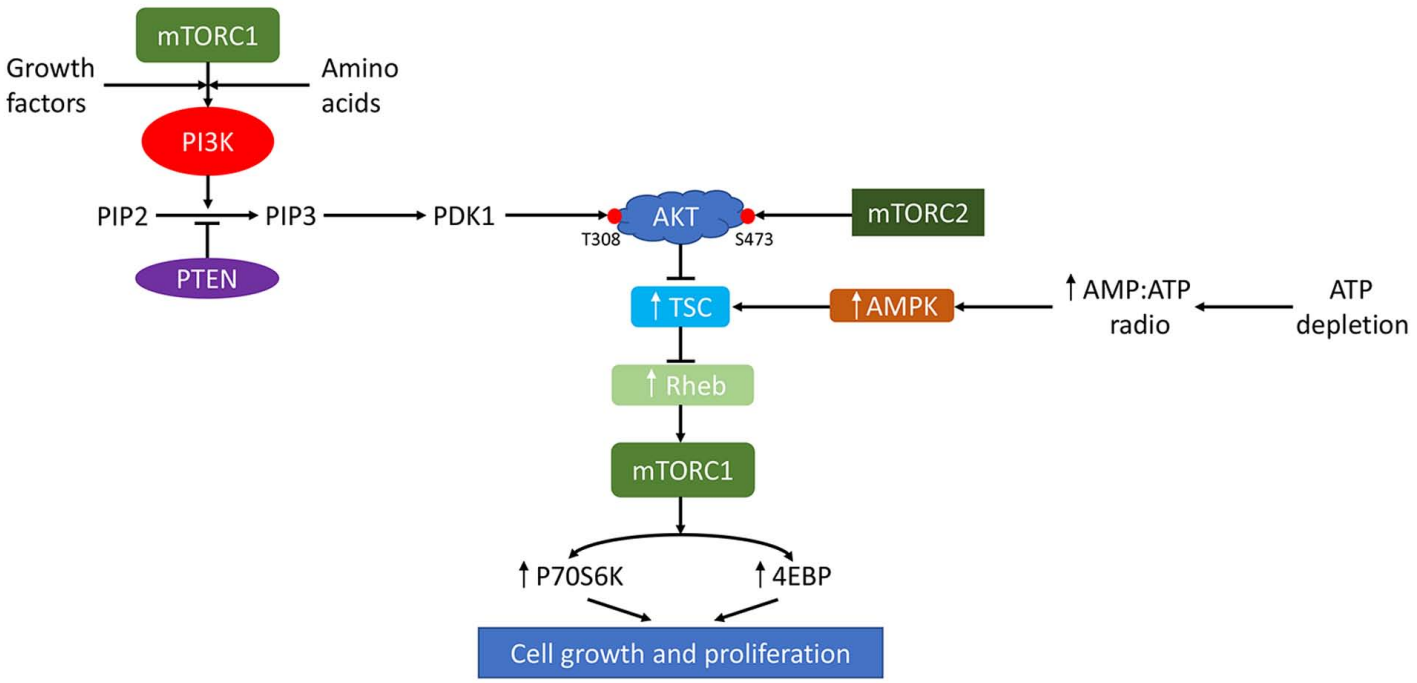

Figure 1. mTOR pathway affects tumor cell growth and proliferation. mTOR consists of two intracellular complexes, mTORC1 and mTORC2. Growth factors and amino acids activate mTORC1, thereby activating lipid kinase PI3K. Phosphorylation of PIP2 by PI3K then produces PIP3, which phosphorylates and activates AKT via the intermediate kinase PDK1. PTEN is a phosphatase that negatively regulates PI3K to dephosphorylate PIP3 back to PIP2. Once this pathway is activated, AKT phosphorylates and inhibits the TSC phosphorylation (AKT can also be activated by mTORC2). TSC is able to negatively regulate mTORC1 by inhibiting Rheb, a GTP-binding protein. AKT can disable this inhibition and activate the mTOR pathway. AMPK reduces cellular ATP storage and increases the AMP:ATP ratio, inhibiting mTOR by the phosphorylation and activation of TSC2. After AKT is activated, mTORC1 phosphorylates p70S6K and 4EBP to promote protein translation and enhance cell growth. mTOR, mechanistic target of rapamycin; mTORC, mTOR complex; PI3K, phosphatidylinositol 3-kinase; PIP2, phosphatidylinositol 4,5-bisphosphate; PIP3, phosphatidylinositol-3,4,5-triphosphate; TSC, tuberous sclerosis complex; Rheb, Ras homolog enriched in brain; PDK1, 3-phosphoinositol-dependent kinase-1; p70S6K, $70 \mathrm{kDa}$ ribosomal protein S6 kinase; 4EBP, eukaryotic translation initiation factor 4E-binding protein 21.

and TNFR2 (51). TNFR1 is mainly expressed in endothelial cells in normal kidneys; it can activate apoptotic signal kinase 1 and NF- $\kappa B$ leading to cell death (52). TNFR2 is expressed primarily on damaged endothelial cells and tubular epithelial cells (TECs), which can activate endothelial/epithelial tyrosine kinase (Etk) and transactivate VEGF receptor 2 (VEGFR2) to promote cell proliferation (53). Aberrant expression of TNFR2 on tumor cells has been found in human RCC (54). The expression of TNFR2 in RCC is associated with grade of malignancy (55). Al-Lamki et al (56) showed that TNF is an autocrine growth factor that selectively promotes clear cell RCC (ccRCC) progression via the TNFR2/Etk/VEGFR2 pathway (56). It was earlier reported that TNF- $\alpha$ selectively activates the TNFR2 response, leading to activation of epithelial cells and Etk, and apparent transactivation of VEGR-2 phosphorylation at $\operatorname{Tyr}(\mathrm{P})-1054-1059$. This pathway promotes the activation of NF- $\kappa B$, which participates in tumor malignancy (55). The activation of NF- $\kappa \mathrm{B}$ triggers transcription of anti-apoptotic proteins, including apoptosis inhibitors [cellular inhibitor of apoptosis proteins (c-IAPs)], cFLICE (procaspase-8) inhibitory protein (c-FLIP), mitogen-activated protein kinase (MAPK)-specific phosphatase and A20 (57). In addition, myeloid-derived suppressor cells (MDSCs) contribute to tumor immune evasion. Recent studies have shown that the generation, accumulation and function of MDSCs depend on TNF-TNFR2 signaling (58-60). Thus, the activation of TNFR2 can promote the progression of RCC.

STAT pathway. The STAT proteins are a family of cytoplasmic transcription factors comprising seven members, STAT1, STAT2, STAT3, STAT4, STAT5a, STAT5b and STAT6.
Since cancer cells are more dependent on the activity of these proteins than their normal counterparts, STAT proteins are considered to be ideal targets for anticancer therapy (61). STAT3 is a potential transcription factor that mediates extracellular signals, such as cytokines and growth factors, by interacting with cell surface polypeptide receptors. Studies have shown that STAT3 promotes RCC occurrence and development (62-64). STAT3 responds to extracellular stimuli and is activated after tyrosine phosphorylation. Phosphorylated STAT3 dimerizes and translocates to the nucleus where it then binds the sequence-specific DNA elements, thereby activating transcription of the target gene (65). Cancer-associated inflammatory mediators, such as the interleukin (IL)- 6 and IL-10 cytokine families, recruit Janus kinase (JAK) family members (JAK1, JAK2 and TYK2) to activate STAT3 phosphorylation after cross-phosphorylation. STAT3 forms homodimers in the cytoplasm, which migrate to the nucleus to regulate gene expression that leads to cancer (66). Numerous lines of evidence have reported that STAT3 regulates genes that play important roles in cell physiology, including the cell cycle, apoptosis, inflammatory immunity, metabolism and angiogenesis (67-69). Enhanced STAT3 activity can block the process of apoptosis and induce the upregulation of Cyclin D1, c-Myc and Survivin expression, resulting in abnormal cell proliferation (70). STAT has also been extensively studied in the field of RCC. Studies have shown that activated STAT3 is a potential regulator of HIF-1, which mediates VEGF expression in RCC $(71,72)$. The aforementioned findings show that STAT affects not only gene expression through the JAK/STAT3 pathway, but also the expression of VEGF by regulating HIF-1. In this way, it affects the occurrence and progression of renal cancer. 


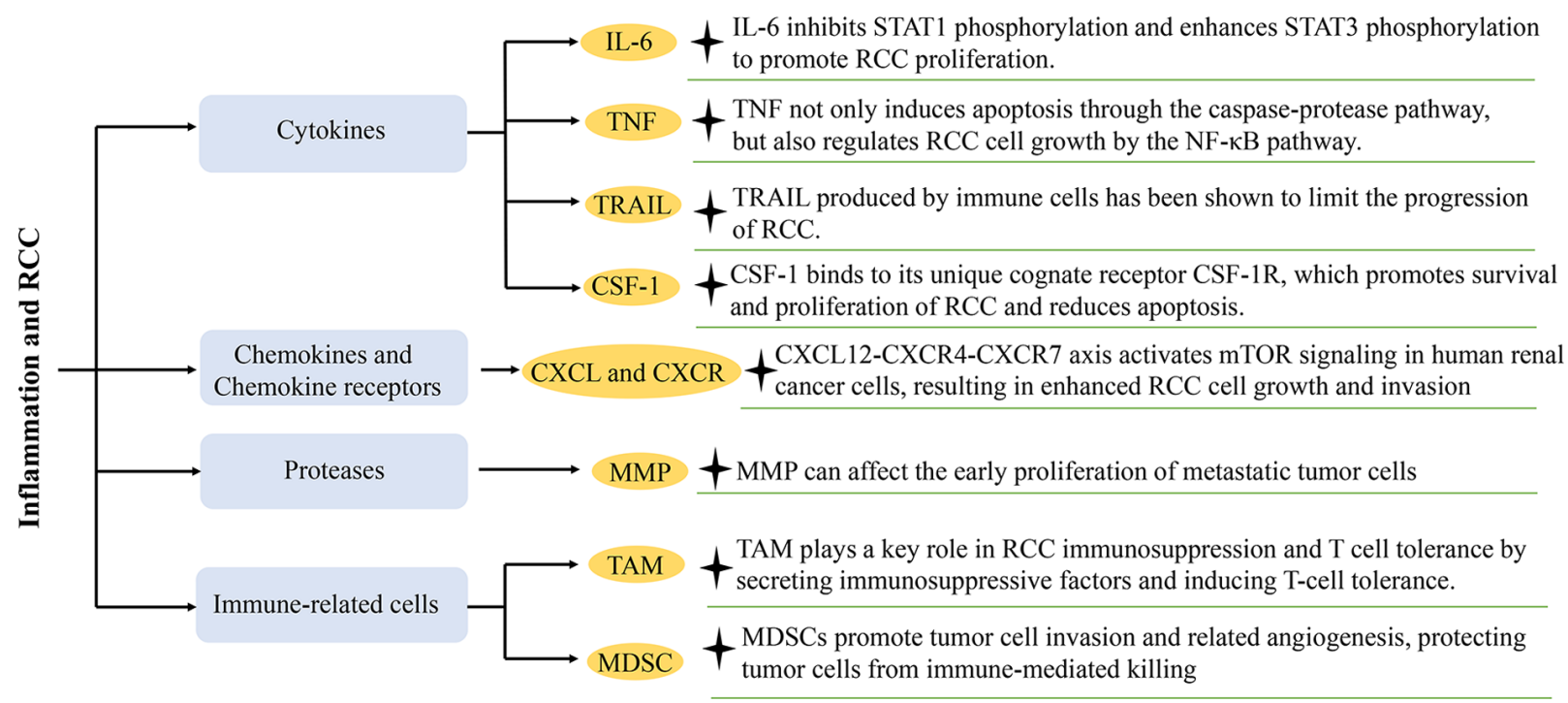

Figure 2. Inflammatory molecules associated with RCC. The role of different inflammatory factors and immune cells in RCC-promoting inflammation and RCC tumor immunity. RCC, renal cell carcinoma; IL, interleukin; STAT, signal transducer and activator of transcription; TNF, tumor necrosis factor; NF- $\mathrm{BB}$, nuclear factor- $\mathrm{KB}$; TRAIL, tumor necrosis factor-related apoptosis-inducing ligand; CSF-1, colony-stimulating factor 1; CSF-1R, CSF-1 receptor; CXCL, chemokine (C-X-C motif) ligand; CXCR, CXC chemokine receptor; MMP, matrix metalloproteinase; TAM, tumor-associated macrophage; MDSC, myeloid-derived suppressor cell.

\section{Role of inflammation factors and immune-related cells in the occurrence and progression of RCC}

A variety of inflammatory factors and immune-related cells are involved in the interactions between inflammation and RCC, where they play an important role. Cytokines, chemokines and other small inflammatory proteins from host cells coordinate intracellular communication in the TME. Continuous crosstalk between cells is critical for tumor growth, invasion, angiogenesis and metastatic spread (9). The present review focuses on the major contributors to tumor-associated inflammation and local immune responses, including cytokines and chemokine receptors, transcription factors and immune-related cells (Fig. 2).

\section{Cytokines}

$I L-6$. IL-6 is an inflammatory cytokine with multiple biological effects; it is composed of 184 amino acids, with a molecular weight of 21-28 kDa. IL-6 has a 4-helix bundle structure consisting of 4 long $\alpha$-helices (73-75). It has been reported that enhancing the production of IL-6 stimulates the expression of proinflammatory factors, such as IL-1, TNF- $\alpha$, interferons, bacterial endotoxin and lipopolysaccharide or viral infection $(76,77)$. Numerous studies have explored the role of IL-6 in kidney functions. Renal cortical tissue and kidney cancer tissue can produce IL-6 (78). IL-6 is expressed in most RCC cell lines and in patient tissues, and it plays an important role in the proliferation of RCC cells (78). Mechanistic studies showed that IL-6 activates IL-6 receptor (IL-6R) and glycoprotein 130 (gp130), causing phosphorylation of the tyrosine kinases JAK1, JAK2 and TYK2. This results in phosphorylation of STAT3 (79). Pathophysiological conditions play an important role in the regulation of IL-6. The transcriptional signal of IL- 6 appears to be activated only during immune stress, and the IL-6/soluble IL-6R complex is usually upregulated in pathophysiological conditions (80). Matsumoto et al (81) indicated that tumor endothelial cells upregulate the expression of gp130 and downregulate the expression of membrane-bound IL-6R through the IL-6/IL-6sR complex, leading to cell proliferation, inhibition of apoptosis and enhancement of tumor development. IL-6 inhibits STAT1 phosphorylation, enhances STAT3 phosphorylation, promotes RCC proliferation and blunts the antitumor effect of IFN (82). Meanwhile, studies have shown that IL-6-activated plasma membrane-associated sialidase (NEU3) may also contribute to the expression of malignant phenotypes in RCC (83) (Fig. 3).

$T N F$.TNF is a potent pro-inflammatory cytokine that mediates complex biological responses, including inflammation, antiviral response, septic shock and apoptotic cell death (84). TNF can trigger apoptosis through the caspase-protease pathway

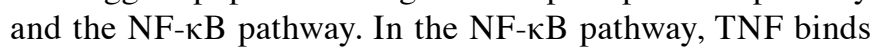
to TNFR to activate atypical protein kinase $\mathrm{C}$ and phosphorylates inhibitor of nuclear factor- $\kappa B$ kinase subunit $\beta$ (IKK $\beta)$. Subsequently, the activated IKK $\beta$ phosphorylates inhibitor of $\mathrm{NF}-\kappa \mathrm{B}(\mathrm{I} \kappa \mathrm{B})$, resulting in ubiquitin-mediated degradation of I $\kappa$ B. NF- $\kappa \mathrm{B}$ is released after I $\mathrm{B}$ degradation and translocated into the nucleus where it activates the transcription of a number of anti-apoptotic genes, including the c-FLIP and c-IAP families $(85,86)$. It has been shown that TNF- $\alpha$ regulates RCC cells growth by modulating the NF- $\mathrm{BB}$-mediated anti-apoptotic pathway (55). Harrison et al (87) used an anti-TNF monoclonal antibody, infliximab, in two phase II clinical trials in patients with locally advanced and metastatic RCC. It was found that targeting TNF may be a beneficial therapeutic approach for cancer management. A previous study has reported that patients with high serum inflammatory cytokine levels in RCC have a poor prognosis, thus, TNF- $\alpha$ can be used as an independent prognostic indicator. Normal TNF- $\alpha$ plasma levels are high predictors of good prognosis in untreated patients (88). 


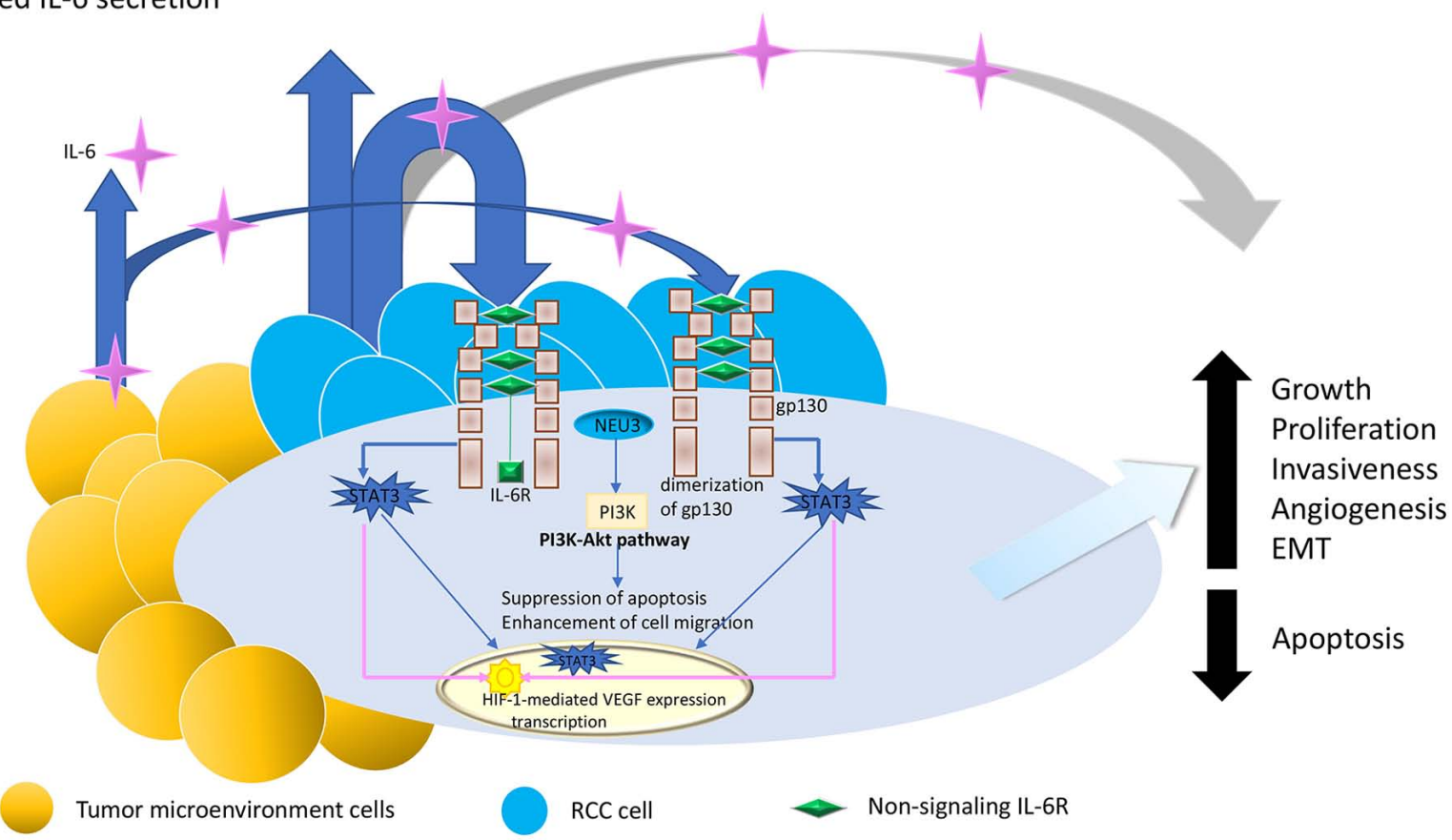

Figure 3. IL-6 pathway promotes RCC development. IL-6 (pink stars) binds first to the membrane-bound non-signaling IL-6R (green diamonds). Non-signaling IL-6R is activated as IL-6R (green square), which can be signal transduced. After recruitment of 2 gp130 (brown-colored rectangular squares) molecules, the signaling complex is formed and signal transduction is induced (brown-colored squares represent 'dimerization of gp130'). Signaling via membrane-bound IL-6R can promote the development of RCC by activating STAT3, a potential regulator of HIF-1-mediated VEGF expression transcription. This may be associated with the proliferation of RCC. Human NEU3 plays an important role in cell differentiation and transmembrane signal transduction, and its expression is associated with IL-6. NEU3 is sensitive to IL-6 signaling via the PI3K pathway. Overexpression of NEU3 can enhance the action of IL-6, inhibit apoptosis and promote cell migration. IL-6, interleukin-6; IL-6R, IL-6 receptor; RCC, renal cell carcinoma; gp130, glycoprotein 130; STAT3, signal transducer and activator of transcription 3; HIF-1, hypoxia-inducible factor 1; VEGF, vascular endothelial growth factor; NEU3, plasma membrane-associated sialidase; PI3K, phosphatidylinositol 3-kinase; EMT, epithelial-mesenchymal transition.

TNF-related apoptosis-inducing ligand (TRAIL). TRAIL is a molecule belonging to the TNF superfamily; it is an effective anticancer agent as it specifically targets cancer cells while retaining normal cells, thereby inducing apoptosis (89). TRAIL can bind to death receptor DR4 and DR5, and assembles a death-inducing signaling complex by recruiting FAS-associated protein associated with death domain and caspase- 8 . Autocatalytic activation of caspase- 8 leads to caspase cascade activation, ultimately leading to cell death (90). In cancer treatment, normal cells highly express decoy receptors DcR1 and DcR2, while cancer cells highly express death receptors DR4 and DR5 (89). TRAIL can bind to DR4 and DR5 and ultimately target cancer cell death (91). The complex formed by the binding of TRAIL to the DcR does not activate the apoptotic signaling pathway. Therefore, there is a weaker influence of TRAIL on the apoptosis of normal cells than cancer cells. Furthermore, TRAIL produced by immune cells has been shown to limit the progression of RCC (92).

Colony-stimulating factor 1 (CSF-1). CSF-1 is an important regulator of macrophage homeostasis (93). Co-expression of CSF-1 and CSF-1 receptor (CSF-1R) promotes proliferation and anti-apoptosis during regeneration of renal TECs. The CSF-1-dependent autocrine pathway is an important pathway for RCC growth. High levels of CSF-1 and tumor-associated macrophages (TAMs) are associated with a poor cancer prognosis. Co-expression of CSF-1 and CSF-1R on RCCs and adjacent TECs promotes tumor proliferation and tumor metastasis (94). The paracrine interaction between tumor cells and TAMs promotes tumor cell migration, invasion and metastasis, accelerating the spread of tumors in the host $(95,96)$. Tumor-derived CSF-1 regulates TAMs, while CSF-1 and CSF-1R co-expression-regulated macrophages affect the TME of the host $(97,98)$. A study by Dosquet et al (88) indicated that the autocrine CSF-1-dependent RCC mechanism is the core of RCC growth, and that the binding of CSF-1 to its unique cognate receptor CSF-1R promotes the survival and proliferation of RCC, and reduces apoptosis. Moreover, EGF induces CSF-1 and CSF-1R on RCC, thereby promoting tumor cell proliferation and inhibiting tumor cell apoptosis (99). This indicates that CSF-1R signaling promotes the growth of RCC.

\section{Chemokines and chemokine receptor}

Chemokine (C-X-C motif) ligand (CXCL) and CXC chemokine receptor $(C X C R)$. Chemokines are a subfamily of cytokines that contain $\sim 50$ different signaling proteins. Similar to other cytokines, chemokines affect cell behavior through both autocrine and paracrine modes (100). Chemokines and their receptors are involved in the regulation of growth, angiogenesis and metastasis of RCC (101). It has been shown that CXCR4 is an ideal target for tumor diagnosis and treatment (102). The expression of CXCR4 in most cases is associated with tumor-specific survival in ccRCC with VHL mutations. A close association between VHL and CXCR4 has been observed. The VHL disease tumor suppressor (pVHL) is a protein that negatively regulates CXCR4. pVHL can target 
the degradation of HIF under normoxic conditions to prevent CXCR4 expression. This process is inhibited under hypoxic conditions (103-105). A study by Ieranò et al (106) indicated that the CXCL12-CXCR4-CXCR7 axis activates mTOR signaling in human renal cancer cells, resulting in enhanced RCC cell growth and invasion (106). Other studies have shown that the CXCR4-CXCL12-CXCR7 axis also plays a key role in RCC. The activity of CXCR4 is mainly $\gamma$-mediated; however, CXCR7 is considered to be an atypical $\mathrm{G}$ protein-coupled receptor, as it does not cause intracellular $\mathrm{Ca}^{2+}$ release when bound to a ligand (107). Some studies have shown that CXCR7 is a DcR that isolates extracellular CXCL12 or regulates the CXCR4 signaling pathway by forming a CXCR7-CXCR4 heterodimer $(108,109)$. High expression of CXCR7 in human cancer types such as bladder cancer, glioma, colorectal cancer, ovarian cancer and breast cancer, and in tumor-associated blood vessels, may be critical for tumor cell survival, adhesion and growth (110-115). Overall, CXCR4 and CXCR7 are potential molecules affecting the prognosis of RCC (116).

\section{Proteases}

Matrix metalloproteinases (MMPs). MMPs are members of the zinc-dependent endopeptidase family; they regulate signaling pathways that control cell growth, inflammation or angiogenesis. Hence, MMPs participate in molecular communication between tumors and stroma, mediating microenvironmental changes during tumor progression $(117,118)$. Compelling evidence from knockout mouse experiments has shown that MMPs play an important role in acute and chronic inflammation (119). Numerous studies have demonstrated that MMPs can aggregate leukocytes to cause tumor-related inflammation $(120,121)$. Studies have confirmed that MMPs affect the early proliferation of metastatic tumor cells, while tissue inhibitors of MMP (TIMPs) inhibit MMP activity to indirectly regulate tumor cell proliferation $(122,123)$. Among these MMPs, MMP-9 has the most important function in tumors. MMP-9 exhibit higher expression in malignant tumors than in benign or non-invasive tumors, and it also exhibits high expression in RCC; it can denature type I, II and IV collagen, enabling tumor cells to penetrate the basement membrane $(124,125)$. Additionally, membrane type $1 \mathrm{MMP}$ (MT1-MMP/MMP-14) is involved in tumor invasion; it is widely expressed in most malignant tumors, and its overexpression enhances cell invasion ability (126). MT1-MMP not only degrades extracellular matrix molecules such as type I, II and III collagen, vitronectin, laminin-1 and -5 , fibronectin and aggrecan (127), but it also recruits pro-MMP-2 to the cell surface and causes the activation of MMP-2 by cleaving the propeptide sequence (128). A study by Petrella and Brinckerhoff (129) showed that MT1-MMP is the main trigger of type I collagen degradation and the invasiveness of VHL RCC cells expressing MT1-MMP or HIF-2 $\alpha$. In addition, in the absence of VHL, the protein and gene levels of MT1-MMP are significantly upregulated in RCC (130).

\section{Immune-related cells}

TAMs. TAMs are derived from peripheral blood mononuclear cells. Macrophages usually undergo M1 or M2 activation under inflammatory stimuli (131). In RCC, M1 cells produce inflammatory cytokines such as TNF- $\alpha$, IL-6, IL-12 and IL-23, while
M2 cells produce anti-inflammatory cytokines such as IL-10, thereby promoting RCC-related immune dysfunction (132). Santoni et al (133) showed that high TAM infiltration in the RCC microenvironment promotes tumor progression and metastasis by stimulating angiogenesis, tumor growth and cell migration. RCC is a typical hemangioma in which VEGF is significantly upregulated. VEGF, considered to be a chemokine of TAM, supports tumor proliferation. TAM can self-produce VEGF, which increases the accumulation of TAM in tumor sites (134). TAM plays a key role in RCC immunosuppression and T-cell tolerance by secreting immunosuppressive factors and inducing T-cell immunity without response (135).

MDSC. MDSCs are a group of heterogeneous cells derived from the bone marrow, which are preferentially expanded in cancer and have a significant ability to suppress immune cell responses; they primarily inhibit $\mathrm{T}$-cell proliferation and NK-cell activation, and induce differentiation and proliferation of regulatory T cells (136). MDSCs have the ability to inhibit T-cell activation through upregulation of arginase-1 (Arg1) and inducible nitric oxide synthase in monocytic MDSCs, and Arg1 and reactive oxygen species in granulocytic MDSCs (137). The TME affects the progression and metastasis of solid tumors, which consist of tumor cells and other primitive stromal cells $(138,139)$. MDSCs are the main components of the TME, and the increase in blood volume is associated with a shorter patient survival time. Mechanistic studies have shown that MDSCs promote tumor cell survival, associated angiogenesis, invasion and metastasis $(140,141)$. MDSCs also protect tumor cells from immune-mediated killing, establish a TME and interact with tumor cells to promote epithelial-mesenchymal transition to support tumor growth and metastasis (142). A close association between MDSCs and clinical outcomes of cancer patients has been established. MDSCs hold great promise as novel biomarkers for tumor prognosis (143).

\section{Inflammation-associated molecules and clinical prognosis in patients with $\mathrm{RCC}$}

A number of inflammation-related factors, including Th1-related factors (IFN- $\gamma$ ), Th1-related chemokines (monokine induced by IFN- $\gamma$ [MIG], IFN- $\gamma$ inducible protein 10 [IP-10] and IFN- $\gamma$-inducible T-cell A chemoattractant [I-TAC]), Th2-related factors (IL-4) and Th2-associated chemokines (eotaxin and macrophage-derived chemokine [MDC]) are elevated in tumor tissues (138). A variety of inflammatory factors are associated with recurrence in patients, for example, MIG and IFN $\gamma$-mediated mononuclear factors (144).

Inflammation-related factors TNF- $\alpha$, CXCR4 and C-C chemokine receptor type 3 (CCR3) are associated with the prognosis and staging of patients with RCC. For instance, TNF- $\alpha$ is an independent prognostic indicator, and normal levels in plasma can highly predict the good prognosis of untreated RCC patients $(88,145)$. In addition, CXCR4 has significant prognostic value in univariate analysis, and its low expression indicates a good prognosis (146). The high expression of CCR3 in immunohistochemical analysis is associated with the degree of malignancy of the tumor. Upregulation of CCR3 and its ligands may promote tumor cell proliferation (147). In another study, Kallakury et al (148) showed that 
Table I. Main anti-inflammatory agents in RCC.

\begin{tabular}{lll} 
Agent & \multicolumn{1}{c}{ Target/associated pathway } & \multicolumn{1}{c}{ Therapeutic effects } \\
\hline Simvastatin & AKT, mTOR and ERK pathway; & IL -6-induced phosphorylation of JAK2 \\
& and STAT3 pathway & $\begin{array}{l}\text { Inhibit the proliferation and migration of } \\
\text { RCC cells }\end{array}$ \\
ATRA & RAR/RXR pathway; PI3K/AKT pathway & Regulate the cell cycle \\
Nivolumab & PD-1 pathway & Antitumor activity in metastatic RCC \\
LY294002 & PI3K/AKT pathway & Influences tumor cell growth and apoptosis \\
Antibodies against 15-LOX2 & 15-LOX2/15(S)-HETE pathway & Influences the RCC tumor microenvironment
\end{tabular}

RCC, renal cell carcinoma; ATRA, all-trans retinoic acid; mTOR, mechanistic target of rapamycin; ERK, extracellular signal-regulated kinase; IL-6, interleukin-6; JAK2, Janus kinase 2; STAT3, signal transducer and activator of transcription 3; RAR, retinoic acid receptor; RXR, retinoid X receptor; PI3K, phosphatidylinositol 3-kinase; PD-1, programmed death 1; 15-LOX2/15(S)-HETE, 15-lipoxygenase 2/15(S)-hydroxyeicosatetraenoic acid.

increased expression of MMP2, MMP9, TIMP1 and TIMP2 in $\mathrm{RCC}$ correlated with a poor prognosis. In summary, inflammation-related factors may be predictive indicators of $\mathrm{RCC}$ clinical prognosis and have a huge potential role in RCC therapy.

\section{Anti-inflammatory immunotherapy in RCC}

With in-depth basic research and a better understanding of the mechanism of inflammation in RCC, new anti-inflammation-related therapeutics and immunotherapy-related agents may be developed. In recent years, simvastatin, all-trans retinoic acid (ATRA), nivolumab and other immunotherapeutic agents have played a role in the treatment of RCC (Table I).

\section{Anti-inflammation-related agents}

Simvastatin. Simvastatin is a cholesterol-lowering drug for the prevention of cardiovascular disease, and is involved in tumor growth, spread and endothelial function (149). A previous study has reported that the extracellular signal-regulated kinase (ERK)1/2 signaling pathway is a statin-dependent pro-apoptotic mediator (150). Knockdown of ERK can make RCC cells sensitive to simvastatin-induced anticancer effects. Simvastatin can inhibit the proliferation and migration of RCC cells by inhibiting the phosphorylation of AKT, mTOR and ERK; it also exhibits antitumor effects by inhibiting the IL-6-induced phosphorylation of JAK2 and STAT3 (151).

ATRA. ATRA is the active metabolite of vitamin A, involved in cell proliferation, differentiation and apoptosis; its role is mediated by nuclear flavonoid receptors, MAPK and cAMP/cAMP-dependent protein kinase signaling pathways (152). ATRA reduces cell proliferation and alters gene expression through nuclear receptor- and non-receptor-mediated pathways, thereby accelerating cell differentiation and apoptosis. In genomic action, the function of ATRA is mediated by nuclear receptors, particularly retinoic acid receptors (RARs) $(\alpha, \beta$ and $\gamma)$. Nuclear RAR acts as a retinoid-inducible transcription factor, and regulates cell cycle arrest, cell differentiation and cell regulation through heterodimer formation with retinoid X receptor (153). Among the RARs, RAR $\beta$ is a tumor suppressor that is expressed at low levels in a number of cancer types, such as breast and prostate cancer, and whose expression is regulated by ATRA (154). In the non-genomic pathway, ATRA independently activates the transcription of genes involved in the PI3K/AKT pathway in cells, reversing the dysregulation of the PI3K/AKT pathway in most human cancer types. In more detail, this process entails the activation of PI3K by ATRA through G-protein coupled receptors and multiple receptor tyrosine kinases. Activated PI3K catalyzes the production of phosphatidylinositol-3,4,5-triphosphate to promote aggregation and activation of AKT on the membrane (155).

Nivolumab. Nivolumab is a programmed death 1 (PD-1) checkpoint inhibitor that selectively blocks the interaction between PD-1 and PD ligand (PD-L)1/PD-L2 expressed on activated $\mathrm{T}$ cells, thereby preventing T-cell inactivation (156). Expression of PD-L1 as a remote immunomodulator occurs in $20-50 \%$ of human cancer types. A variety of cancer immunotherapies targeting the interaction between PD-L1 and PD-1 have been developed $(157,158)$. PD-L1 effectively inhibits the tumor-killing ability of T cells. Once the PD-L1:PD-1 interaction is blocked, $\mathrm{T}$ cells can quickly restore their effector function. PD-L1 expressed on tumor cells binds to PD-1 on activated effector T cells, and phosphatase SHP-2 is recruited, resulting in inactivation of the PI3K signaling cascade (159). It has been found that PD-L1 or PD-1 inhibitors have a positive effect on the treatment of cancer. Nivolumab exerts antitumor activity in metastatic RCC (160). The immunotherapeutic agent ipilimumab is a human cytotoxic T-lymphocyte antigen-4 (CTLA-4) immune checkpoint inhibitor antibody, which can prevent CD80 and CD86 ligands on antigen-presenting cells from binding to the CTLA-4 receptor on activated $\mathrm{T}$ cells, thereby preventing the downregulation of antitumor T cell activity (161). CTLA-4 plays a significant role in early immune response, primarily occurring in lymphoid tissues, while PD-1, whose expression is upregulated after T-cell activation in peripheral tissues, is more involved in late immune response (162). The combined application of CTLA-4 and PD-1 blockers can synergistically activate the antitumor immune response and increase the response rate of patients (163). Thus, 
a combination of nivolumab and ipilimumab will effectively control tumor development with a good safety profile (164).

Immunotherapy for $R C C$. Emerging clinical data reveals that immunotherapy has great potential in the treatment of cancer. Associated studies have shown that a series of gradual and repeated immune response events, defined as the cancer-immune cycle, can effectively kill cancer cells. In the first step of this process, tumor antigens are captured by dendritic cells (DCs) for processing (165). Proinflammatory cytokines and factors released by dying tumor cells can be used as a designated immune signal to avoid induction of tumor tolerance antigens (step 1) $(166,167)$. DCs then present the captured antigen on the major histocompatibility complex I (MHCI) and MHCII molecules to the $\mathrm{T}$ cells (step 2) (168). This initiates and activates the effector T-cell response (step 3) (169). This is followed by the entry (step 4) and invasion (step 5) of the tumor bed by the activated effector T cells (170), which then recognize and bind to specific cancer cells (step 6) and kill them (step 7) (171). Subsequently, the tumor-associated antigens released from the dying cells amplify the cycle of immune response and make it more widespread and repetitive (172).

The entire immune cycle is enhanced through the positive regulatory signalor suppressed via the negative regulatory signal in the aforementioned steps during therapeutic treatments. The first phase of treatment corresponds to chemotherapy, radiotherapy and targeted therapy. These treatments induce immune cell death by activating the immune system (173). The second phase corresponds to use of cancer vaccines, which rely on tumor cell-associated antigens to awaken the immune system against cancer (174). The third phase is mainly associated with CTLA-4 inhibitors. CTLA-4 is a receptor found on the surface of activated T-cells, which predominantly acts by competing with $\mathrm{CD} 28$ receptors for binding to $\mathrm{B} 7$ ligands on antigen presenting cells (APCs). In the process of $\mathrm{T}$ cell activation, $\mathrm{CD} 28$ receptors on the T-cells bind to the $\mathrm{B} 7$ ligands on APCs and provide the essential second activation signal for T-cell. However, CTLA-4 receptors can competitively bind to B7 ligands with higher affinity, resulting in the lack of second activation signal. Lack of the second activation signal in the presence of CTLA-4 receptors would lead to anergy in T-cells $(163,175)$. The fourth phase involves the transport of $\mathrm{T}$ lymphocytes, and no intervention is available at this stage. The fifth stage is predominantly through anti-VEGF treatment to enhance $\mathrm{T}$ cell transport and tumor bed infiltration. The transfer of activated $\mathrm{T}$ cells from the lymph nodes into circulation and then to the tumor requires a series of steps. VEGF promotes the formation of abnormal tumor blood vessels, which can negatively affect the transmigration of T-cells from lymph nodes to the tumor bed (176). In addition, the blockade of VEGF can increase the expression of E-selectin on tumor vascular endothelium and down-regulate the Fas ligand on vascular endothelial cells, ultimately promoting the increased of T-cell tumor infiltration (177). The sixth phase involves CAR-T-cell therapy, which is to generate a powerful immune-mediated anti-tumor response through the in vitro manipulation of T-cells (178). This treatment is achieved through the selection and expansion of tumor-infiltrating lymphocytes (TILs), or through gene transfer of a synthetic
TCR (sTCR) or a chimeric antigen receptor (CAR) into T-cells (179). The seventh stage corresponds to PD-1/PD-L1 inhibitor treatment (180). Immunotherapy has successfully been applied to RCC in recent years (172).

In addition, it has been found that inhibiting the inflammatory pathway is an effective approach to suppress the progression of RCC. Thus agents, such as LY294002, that inhibit the PI3K/AKT signaling cascade may benefit patients with RCC (181). Activation of the 15-lipoxygenase 2/15(S)-hydroxyeicosatetraenoic acid pathway increases the metabolism of arachidonic acid in the RCC TME, compromising the function of the recruited immune cells, thereby promoting local immunosuppression and tumor escape (182).

\section{Conclusions and prospects}

Inflammation influences all aspects of tumor occurrence and progression, as well as the tumor response to treatment. In the early stages of tumor formation, inflammatory cells play a pro-tumor development role, creating favorable conditions for tumor growth (183). Chemokines and cytokines provided by inflammatory cells affect the entire tumor organ and regulate the growth, migration and differentiation of cells in the TME. In the later stages of tumorigenesis, tumor cells also switch inflammatory mechanisms, such as the production of chemokines and MMP, favoring tumor proliferation and metastasis $(119,184)$. However, aggregation of inflammatory cells may suppress tumor growth (7).

Accumulating evidence indicates that the TME harbors multiple inflammatory cells that regulate tumor cell growth, proliferation, survival and migration (185). The aforementioned inflammation-related pathways (the VHL, mTOR, TNF and STAT pathways) can promote the occurrence and progression of RCC by activating the inflammatory response. Pro-inflammatory cytokines (IL-6, TNF and CSF-1) and chemokines (CXCL and CXCR) are involved in tumor-related pathways and promote the proliferation of RCC cells. When highly expressed, they confer a poor prognosis for RCC. TRAIL expression has been recorded as a prognostic factor for improved RCC-specific survival (186). As a key participant in the molecular communication between tumors and stroma, MMP overexpression enhances RCC cell invasion ability (187). TAM cells and MDSCs support the growth and metastasis of RCC by suppressing the ability of immune cell responses. In terms of the therapy, agents targeting inflammation (simvastatin, ATRA, nivolumab, PI3K/AKT pathway inhibitor and cancer immune cycle inhibitors) have shown great promise in prolonging the survival time of RCC patients. Understanding the nature of inflammation and RCC will reveal important targets for developing treatments of $\operatorname{RCC}(9,188)$.

On the basis of recent technological advances and in-depth research on the pathology and mechanism of RCC, new findings and breakthroughs have been reported. The association between inflammation and RCC phenotypes has become the new hotspot of current cancer research $(9,189,190)$. Numerous studies have demonstrated that the expression of most inflammation-related factors is associated with the poor prognosis of RCC and that immune-infiltrating cell profiles can also predict the prognosis of patients $(72,92,191)$. Research on 
immune-targeted treatments has become one of the hotspots in basic and clinical research, providing hope for tumor treatment. In the past 12 years, the medical treatment of RCC has transitioned from non-specific immune methods to targeted therapy for VEGF to new immunotherapeutic agents (192). The interaction between tumor immune status and cancer-related systemic inflammation is essential for the treatment of RCC. Therapies targeted at inflammatory pathways are likely to be a new direction for RCC treatment.

\section{Acknowledgements}

Not applicable.

\section{Funding}

No funding was received.

\section{Availability of data and materials}

Not applicable.

\section{Authors' contributions}

JS, KC and XZ conceived the present study. JS, KW and ZX drafted the manuscript. CY, CW, QC, HYu, XM and $\mathrm{ZC}$ made substantial contributions to the interpretation and analysis of the data, drafting the study and revising it critically for important intellectual content. KX and HYa were major contributors in the revision of the manuscript. All authors read and approved the final manuscript.

\section{Ethics approval and consent to participate}

Not applicable.

\section{Patient consent for publication}

Not applicable.

\section{Competing interests}

The authors declare that they have no competing interests.

\section{References}

1. Wiechno P,Kucharz J, Sadowska M, MichalskiW,Sikora-Kupis B, Jonska-Gmyrek J, Poniatowska G, Nietupski K, Ossolinski K and Demkow T: Contemporary treatment of metastatic renal cell carcinoma. Med Oncol 35: 156, 2018.

2. Bray F, Ferlay J, Soerjomataram I, Siegel RL, Torre LA and Jemal A: Global cancer statistics 2018: GLOBOCAN estimates of incidence and mortality worldwide for 36 cancers in 185 countries. CA Cancer J Clin 68: 394-424, 2018.

3. Hammers HJ, Plimack ER, Infante JR, Rini BI, McDermott DF, Lewis LD, Voss MH, Sharma P, Pal SK, Razak ARA, et al Safety and efficacy of nivolumab in combination with ipilimumab in metastatic renal cell carcinoma: The CheckMate 016 study. J Clin Oncol 35: 3851-3858, 2017.

4. Siegel RL, Miller KD and Jemal A: Cancer statistics, 2016. CA Cancer J Clin 66: 7-30, 2016.

5. Galdiero MR, Marone G and Mantovani A: Cancer inflammation and cytokines. Cold Spring Harb Perspect Biol 10: a028530, 2018.
6. Kay J, Thadhani E, Samson L and Engelward B: Inflammation-induced DNA damage, mutations and cancer. DNA Repair (Amst) 83: 102673, 2019.

7. Korniluk A, Koper O, Kemona H and Dymicka-Piekarska V: From inflammation to cancer. Ir J Med Sci 186: 57-62, 2017.

8. Ha H, Debnath B and Neamati N: Role of the CXCL8-CXCR1/2 axis in cancer and inflammatory diseases. Theranostics 7: 1543-1588, 2017.

9. Brighi N, Farolfi A, Conteduca V, Gurioli G, Gargiulo S, Gallà V, Schepisi G, Lolli C, Casadei C and De Giorgi U: The interplay between inflammation, anti-angiogenic agents, and immune checkpoint inhibitors: Perspectives for renal cell cancer treatment. Cancers (Basel) 11: 1935, 2019.

10. Nakamura K and Smyth MJ: Targeting cancer-related inflammation in the era of immunotherapy. Immunol Cell Biol 95: 325-332, 2017.

11. Balkwill $\mathrm{F}$ and Mantovani A: Inflammation and cancer: Back to Virchow? Lancet 357: 539-545, 2001.

12. Ngabire D and Kim GD: Autophagy and inflammatory response in the tumor microenvironment. Int J Mol Sci 18: 2016, 2017.

13. Todoric J, Antonucci L and Karin M: Targeting inflammation in cancer prevention and therapy. Cancer Prev Res (Phila) 9: 895-905, 2016.

14. Borroni EM, Savino B, Bonecchi R and Locati M: Chemokines sound the alarmin: The role of atypical chemokine in inflammation and cancer. Semin Immunol 38: 63-71, 2018.

15. Elinav E, Nowarski R, Thaiss CA, Hu B, Jin C and Flavell RA: Inflammation-induced cancer: Crosstalk between tumours, immune cells and microorganisms. Nat Rev Cancer 13: 759-771, 2013.

16. Marelli G, Sica A, Vannucci L and Allavena P: Inflammation as target in cancer therapy. Curr Opin Pharmacol 35: 57-65, 2017.

17. Greten FR and Grivennikov SI: Inflammation and cancer: Triggers, mechanisms, and consequences. Immunity 51: 27-41, 2019.

18. Munn LL: Cancer and inflammation. Wiley Interdiscip Rev Syst Biol Med 9, 2017.

19. Murata M: Inflammation and cancer. Environ Health Prev Med 23: 50, 2018.

20. Urban-Wojciuk Z, Khan MM, Oyler BL, Fåhraeus R, Marek-Trzonkowska N, Nita-Lazar A, Hupp TR and Goodlett DR: The role of TLRs in anti-cancer immunity and tumor rejection. Front Immunol 10: 2388, 2019.

21. Kunnumakkara AB, Sailo BL, Banik K, Harsha C, Prasad S, Gupta SC, Bharti AC and Aggarwal BB: Chronic diseases, inflammation, and spices: How are they linked? J Transl Med 16: $14,2018$.

22. Kundu JK and Surh YJ: Emerging avenues linking inflammation and cancer. Free Radic Biol Med 52: 2013-2037, 2012.

23. Taniguchi $K$ and Karin M: NF- $\mathrm{B}$, inflammation, immunity and cancer: Coming of age. Nat Rev Immunol 18: 309-324, 2018.

24. Hu YS, Han X and Liu XH: STAT3: A potential drug target for tumor and inflammation. Curr Top Med Chem 19: 1305-1317, 2019.

25. Hsieh JJ, Purdue MP, Signoretti S, Swanton C, Albiges L, Schmidinger M, Heng DY, Larkin J and Ficarra V: Renal cell carcinoma. Nat Rev Dis Primers 3: 17009, 2017.

26. Martínez-Sáez O, Gajate Borau P, Alonso-Gordoa T, Molina-Cerrillo J and Grande E: Targeting HIF-2 $\alpha$ in clear cell renal cell carcinoma: A promising therapeutic strategy. Crit Rev Oncol Hematol 111: 117-123, 2017.

27. Tarade D and Ohh M: The HIF and other quandaries in VHL disease. Oncogene 37: 139-147, 2018.

28. Chappell JC, Payne LB and Rathmell WK: Hypoxia, angiogenesis, and metabolism in the hereditary kidney cancers. J Clin Invest 129: 442-451, 2019.

29. Duan C: Hypoxia-inducible factor 3 biology: Complexities and emerging themes. Am J Physiol Cell Physiol 310: C260-C269, 2016.

30. Choudhry $\mathrm{H}$ and Harris AL: Advances in hypoxia-inducible factor biology. Cell Metab 27: 281-298, 2018.

31. Strowitzki MJ, Cummins EP and Taylor CT: Protein hydroxylation by hypoxia-inducible factor (HIF) hydroxylases: Unique or Ubiquitous? Cells 8: 384, 2019.

32. Yu Y, Yu Q and Zhang X: Allosteric inhibition of HIF-2 $\alpha$ as a novel therapy for clear cell renal cell carcinoma. Drug Discov Today 24: 2332-2340, 2019.

33. Schödel J, Grampp S, Maher ER, Moch H, Ratcliffe PJ, Russo P and Mole DR: Hypoxia, hypoxia-inducible transcription factors, and renal cancer. Eur Urol 69: 646-657, 2016. 
34. Qureshi AS and Ali S: Review: Warburg effect and renal cancer caused by errs in fumarate hydratase encoding gene. Pak J Pharm Sci 32: 743-749, 2019.

35. Bao Y, Wang Z, Liu B, Lu X, Xiong Y, Shi J, Li P, Chen J, Zhang Z, Chen M, et al: A feed-forward loop between nuclear translocation of CXCR4 and HIF-1 $\alpha$ promotes renal cell carcinoma metastasis. Oncogene 38: 881-895, 2019.

36. Mossmann D, Park S and Hall MN: mTOR signalling and cellular metabolism are mutual determinants in cancer. Nat Rev Cancer 18: 744-757, 2018.

37. Hua H, Kong Q, Zhang H, Wang J, Luo T and Jiang Y: Targeting mTOR for cancer therapy. J Hematol Oncol 12: 71, 2019.

38. Murugan AK: mTOR: Role in cancer, metastasis and drug resistance. Semin Cancer Biol 59: 92-111, 2019.

39. Saxton RA and Sabatini DM: mTOR signaling in growth, metabolism, and disease. Cell 168: 960-976, 2017

40. Kim LC, Cook RS and Chen J: mTORC1 and mTORC 2 in cancer and the tumor microenvironment. Oncogene 36: 2191-2201, 2017.

41. Song M, Bode AM, Dong Z and Lee MH: AKT as a therapeutic target for cancer. Cancer Res 79: 1019-1031, 2019.

42. Lieberthal $\mathrm{W}$ and Levine JS: The role of the mammalian target of rapamycin (mTOR) in renal disease. J Am Soc Nephrol 20 2493-2502, 2009.

43. Deng W, Han W, Fan T, Wang X, Cheng Z, Wan B and Chen J: Scutellarin inhibits human renal cancer cell proliferation and migration via upregulation of PTEN. Biomed Pharmacother 107: $1505-1513,2018$

44. Figlin RA, Kaufmann I and Brechbiel J: Targeting PI3K and mTORC2 in metastatic renal cell carcinoma: New strategies for overcoming resistance to VEGFR and mTORC1 inhibitors. Int J Cancer 133: 788-796, 2013.

45. Ben-Sahra I and Manning BD: mTORC1 signaling and the metabolic control of cell growth. Curr Opin Cell Biol 45: 72-82, 2017.

46. Duran I, Lambea J, Maroto P, González-Larriba JL, Flores L, Granados-Principal S, Graupera M, Sáez B, Vivancos A and Casanovas O: Resistance to targeted therapies in renal cancer: The importance of changing the mechanism of action. Target Oncol 12: 19-35, 2017.

47. Poletto V, Rosti V, Biggiogera M, Guerra G, Moccia F and Porta C: The role of endothelial colony forming cells in kidney cancer's pathogenesis, and in resistance to anti-VEGFR agents and mTOR inhibitors: A speculative review. Crit Rev Oncol Hematol 132: 89-99, 2018.

48. Ma WW and Jimeno A: Temsirolimus. Drugs Today (Barc) 43 : 659-669, 2007.

49. Bedke J, Stühler V, Stenzl A and Brehmer B: Immunotherapy for kidney cancer: Status quo and the future. Curr Opin Urol 28 $8-14,2018$.

50. Wajant $\mathrm{H}$ and Beilhack A: Targeting regulatory $\mathrm{T}$ cells by addressing tumor necrosis factor and its receptors in allogeneic hematopoietic cell transplantation and cancer. Front Immunol 10 $2040,2019$.

51. Martínez-Reza I, Díaz L and García-Becerra R: Preclinical and clinical aspects of TNF- $\alpha$ and its receptors TNFR1 and TNFR2 in breast cancer. J Biomed Sci 24: 90, 2017.

52. Ting AT and Bertrand MJM: More to life than NF- $\kappa B$ in TNFR1 signaling. Trends Immunol 37: 535-545, 2016.

53. Mehta AK, Gracias DT and Croft M: TNF activity and T cells Cytokine 101: 14-18, 2018

54. Wang J and Al-Lamki RS: Tumor necrosis factor receptor 2: Its contribution to acute cellular rejection and clear cell renal carcinoma. Biomed Res Int 2013: 821310, 2013.

55. Qi $\mathrm{H}$ and Ohh M: The von Hippel-Lindau tumor suppressor protein sensitizes renal cell carcinoma cells to tumor necrosis factor-induced cytotoxicity by suppressing the nuclear factor-kappaB-dependent antiapoptotic pathway. Cancer Res 63: 7076-7080, 2003.

56. Al-Lamki RS, Sadler TJ, Wang J, Reid MJ, Warren AY, Movassagh M, Lu W, Mills IG, Neal DE, Burge J, et al: Tumor necrosis factor receptor expression and signaling in renal cell carcinoma. Am J Pathol 177: 943-954, 2010.

57. Borghi A, Verstrepen L and Beyaert R: TRAF2 multitasking in $\mathrm{TNF}$ receptor-induced signaling to NF- $\mathrm{B}$, MAP kinases and cell death. Biochem Pharmacol 116: 1-10, 2016

58. Zhao X, Rong L, Zhao X, Li X, Liu X, Deng J, Wu H, Xu X, Erben U, Wu P, et al: TNF signaling drives myeloid-derived suppressor cell accumulation. J Clin Invest 122: 4094-4104, 2012.

59. Sheng Y, Li F and Qin Z: TNF receptor 2 makes tumor necrosis factor a friend of tumors. Front Immunol 9: 1170, 2018
60. Zhang S, Yang X, Wang L and Zhang C: Interplay between inflammatory tumor microenvironment and cancer stem cells. Oncol Lett 16: 679-686, 2018.

61. Trivedi S and Starz-Gaiano M: Drosophila Jak/STAT signaling: Regulation and relevance in human cancer and metastasis. Int J Mol Sci 19: 4056, 2018.

62. Chen Y, Zhu Y, Sheng Y, Xiao J, Xiao Y, Cheng N, Chai Y, Wu X, Zhang S and Xiang T: SIRT1 downregulated FGB expression to inhibit RCC tumorigenesis by destabilizing STAT3. Exp Cell Res 382: 111466, 2019.

63. Liu Y, Wang JX, Nie ZY, Wen Y, Jia XJ, Zhang LN, Duan HJ and Shi YH: Upregulation of ERp57 promotes clear cell renal cell carcinoma progression by initiating a STAT3/ILF3 feedback loop. J Exp Clin Cancer Res 38: 439, 2019.

64. Wei X, Yu L and Li Y: PBX1 promotes the cell proliferation via JAK2/STAT3 signaling in clear cell renal carcinoma. Biochem Biophys Res Commun 500: 650-657, 2018.

65. Johnson DE, O'Keefe RA and Grandis JR: Targeting the IL-6/ JAK/STAT3 signalling axis in cancer. Nat Rev Clin Oncol 15: 234-248, 2018

66. Huynh J, Etemadi N, Hollande F, Ernst M and Buchert M: The JAK/STAT3 axis: A comprehensive drug target for solid malignancies. Semin Cancer Biol 45: 13-22, 2017.

67. Fathi N, Rashidi G, Khodadadi A, Shahi S and Sharifi S: STAT3 and apoptosis challenges in cancer. Int J Biol Macromol 117 993-1001, 2018

68. Guanizo AC, Fernando CD, Garama DJ and Gough DJ: STAT3: A multifaceted oncoprotein. Growth Factors 36: 1-14, 2018.

69. Galoczova M, Coates P and Vojtesek B: STAT3, stem cells, cancer stem cells and p63. Cell Mol Biol Lett 23: 12, 2018.

70. Huynh J, Chand A, Gough D and Ernst M: Therapeutically exploiting STAT3 activity in cancer - using tissue repair as a road map. Nat Rev Cancer 19: 82-96, 2019.

71. Yeung YT, Aziz F, Guerrero-Castilla A and Arguelles S: Signaling pathways in inflammation and anti-inflammatory therapies. Curr Pharm Des 24: 1449-1484, 2018.

72. Wang Y, Fu D, Chen Y, Su J, Wang Y, Li X, Zhai W, Niu Y, Yue D and Geng H: G3BP1 promotes tumor progression and metastasis through IL-6/G3BP1/STAT3 signaling axis in renal cell carcinomas. Cell Death Dis 9: 501, 2018.

73. Taher MY, Davies DM and Maher J: The role of the interleukin (IL)-6/IL-6 receptor axis in cancer. Biochem Soc Trans 46: $1449-1462,2018$

74. Kampan NC, Xiang SD, McNally OM, Stephens AN, Quinn MA and Plebanski M: Immunotherapeutic interleukin-6 or interleukin-6 receptor blockade in cancer: Challenges and opportunities. Curr Med Chem 25: 4785-4806, 2018.

75. Ray K, Ujvari B, Ramana V and Donald J: Cross-talk between EGFR and IL-6 drives oncogenic signaling and offers therapeutic opportunities in cancer. Cytokine Growth Factor Rev 41 $18-27,2018$

76. Jordan SC, Choi J, Kim I, Wu G, Toyoda M, Shin B and Vo A Interleukin-6, a cytokine critical to mediation of inflammation, autoimmunity and allograft rejection: Therapeutic implications of IL-6 receptor blockade. Transplantation 101: 32-44, 2017.

77. Jones SA and Jenkins BJ: Recent insights into targeting the IL-6 cytokine family in inflammatory diseases and cancer. Nat Rev Immunol 18: 773-789, 2018

78. Kamińska K, Czarnecka AM, Escudier B, Lian F and Szczylik C: Interleukin-6 as an emerging regulator of renal cell cancer. Urol Oncol 33: 476-485, 2015.

79. Qi QR and Yang ZM: Regulation and function of signal transducer and activator of transcription 3. World J Biol Chem 5: 231-239, 2014.

80. Jones SA, Horiuchi S, Topley N, Yamamoto N and Fuller GM: The soluble interleukin 6 receptor: Mechanisms of production and implications in disease. FASEB J 15: 43-58, 2001.

81. Matsumoto S, Hara T, Mitsuyama K, Yamamoto M, Tsuruta O, Sata M, Scheller J, Rose-John S, Kado S and Takada T: Essential roles of IL-6 trans-signaling in colonic epithelial cells, induced by the IL-6/soluble-IL- 6 receptor derived from lamina propria macrophages, on the development of colitis-associated premalignant cancer in a murine model. J Immunol 184: 1543-1551, 2010.

82. Oguro T, Ishibashi K, Sugino T, Hashimoto K, Tomita S Takahashi N, Yanagida T, Haga N, Aikawa K, Suzutani T, et al: Humanised antihuman IL-6R antibody with interferon inhibits renal cell carcinoma cell growth in vitro and in vivo through suppressed SOCS3 expression. Eur J Cancer 49: 1715-1724, 2013. 
83. Ueno S, Saito S, Wada T, Yamaguchi K, Satoh M, Arai Y and Miyagi T: Plasma membrane-associated sialidase is up-regulated in renal cell carcinoma and promotes interleukin-6-induced apoptosis suppression and cell motility. J Biol Chem 281: 7756-7764, 2006.

84. Annibaldi A and Meier P: Checkpoints in TNF-induced cell death: Implications in inflammation and cancer. Trends Mol Med 24: 49-65, 2018

85. Patel HJ and Patel BM: TNF- $\alpha$ and cancer cachexia: Molecular insights and clinical implications. Life Sci 170: 56-63, 2017.

86. Josephs SF, Ichim TE, Prince SM, Kesari S, Marincola FM, Escobedo AR and Jafri A: Unleashing endogenous TNF-alpha as a cancer immunotherapeutic. J Transl Med 16: 242, 2018.

87. Harrison ML, Obermueller E, Maisey NR, Hoare S, Edmonds K, Li NF, Chao D, Hall K, Lee C, Timotheadou E, et al: Tumor necrosis factor alpha as a new target for renal cell carcinoma: Two sequential phase II trials of infliximab at standard and high dose. J Clin Oncol 25: 4542-4549, 2007.

88. Dosquet C, Coudert MC, Lepage E, Cabane J and Richard F: Are angiogenic factors, cytokines, and soluble adhesion molecules prognostic factors in patients with renal cell carcinoma? Clin Cancer Res 3: 2451-2458, 1997.

89. Wong SHM, Kong WY, Fang CM, Loh HS, Chuah LH, Abdullah S and Ngai SC: The TRAIL to cancer therapy: Hindrances and potential solutions. Crit Rev Oncol Hematol 143: 81-94, 2019.

90. von Karstedt S, Montinaro A and Walczak H: Exploring the TRAILs less travelled: TRAIL in cancer biology and therapy. Nat Rev Cancer 17: 352-366, 2017.

91. Yuan X, Gajan A, Chu Q, Xiong H,Wu K and Wu GS: Developing TRAIL/TRAIL death receptor-based cancer therapies. Cancer Metastasis Rev 37: 733-748, 2018.

92. Xu YM, Brooks AD, Wijeratne EM, Henrich CJ, Tewary P, Sayers TJ and Gunatilaka AA: $17 \beta$-Hydroxywithanolides as sensitizers of renal carcinoma cells to tumor necrosis factor- $\alpha$ related apoptosis inducing ligand (TRAIL) mediated apoptosis: Structure-activity relationships. J Med Chem 60: 3039-3051, 2017

93. Cannarile MA, Weisser M, Jacob W, Jegg AM, Ries CH and Rüttinger D: Colony-stimulating factor 1 receptor (CSF1R) inhibitors in cancer therapy. J Immunother Cancer 5: 53, 2017.

94. Menke J, Kriegsmann J, Schimanski CC, Schwartz MM Schwarting A and Kelley VR: Autocrine CSF-1 and CSF-1 receptor coexpression promotes renal cell carcinoma growth Cancer Res 72: 187-200, 2012

95. Ngambenjawong C, Gustafson $\mathrm{HH}$ and Pun SH: Progress in tumor-associated macrophage (TAM)-targeted therapeutics. Adv Drug Deliv Rev 114: 206-221, 2017.

96. Cassetta L, Fragkogianni S, Sims AH, Swierczak A, Forrester LM, Zhang H, Soong DYH, Cotechini T, Anur P, Lin EY, et al: Human tumor-associated macrophage and monocyte transcriptional landscapes reveal cancer-specific reprogramming, biomarkers, and therapeutic targets. Cancer Cell 35: 588-602.e10, 2019.

97. Achkova D and Maher J: Role of the colony-stimulating factor (CSF)/CSF-1 receptor axis in cancer. Biochem Soc Trans 44: 333-341, 2016.

98. Peyraud F, Cousin S and Italiano A: CSF-1R inhibitor development: Current clinical status. Curr Oncol Rep 19: 70, 2017.

99. Li X, Qin Z, Xue J, Zhang J, Zheng Y, Xu W, Xu T and Zou Q Genetic variants in macrophage colony-stimulating factor are associated with risk of renal cell carcinoma in a Chinese population. Int J Biol Markers 33: 321-328, 2018.

100. Nagarsheth N, Wicha MS and Zou W: Chemokines in the cancer microenvironment and their relevance in cancer immunotherapy. Nat Rev Immunol 17: 559-572, 2017.

101. Cimadamore A, Scarpelli M, Piva F, Massari F, Gasparrini S, Doria A, Cheng L, Lopez-Beltran A and Montironi R: Activity of chemokines in prostate and renal tumors and their potential role as future therapeutic targets. Future Oncol 13: 1105-1114, 2017.

102. Zhou W, Guo S, Liu M, Burow ME and Wang G: Targeting CXCL12/CXCR4 Axis in Tumor Immunotherapy. Curr Med Chem 26: 3026-3041, 2019.

103. Si X,MaJ,YuF,ZhaoH,Huang H and Sun YW: Clinicopathological and prognostic significance of CXCR4 high expression in renal cell carcinoma: A meta-analysis and literature review. Int J Surg 71 $12-18,2019$.

104. Micucci C, Matacchione G, Valli D, Orciari S and Catalano A: HIF $2 \alpha$ is involved in the expansion of CXCR4-positive cancer stem-like cells in renal cell carcinoma. Br J Cancer 113: $1178-1185,2015$.
105. Elhence P: A Commentary on 'Clinico-pathological and prognostic significance of CXCR4 high expression in renal cell carcinoma: A meta-analysis and literature review' (Int J Surg 2019; 71: 12-18). Int J Surg 72: 214-215, 2019.

106. Ieranò $C$, Santagata $S$, Napolitano M, Guardia F, Grimaldi A, Antignani E, Botti G, Consales C, Riccio A, Nanayakkara M, et al: CXCR4 and CXCR7 transduce through mTOR in human renal cancer cells. Cell Death Dis 5: e1310, 2014.

107. Adlere I, Caspar B, Arimont M, Dekkers S, Visser K, Stuijt J, de Graaf C, Stocks M, Kellam B, Briddon S, et al: Modulators of CXCR4 and CXCR7/ACKR3 function. Mol Pharmacol 96 737-752, 2019

108. Salazar N and Zabel BA: Support of tumor endothelial cells by chemokine receptors. Front Immunol 10: 147, 2019.

109. Morein D, Erlichman N and Ben-Baruch A: Beyond cell motility: The expanding roles of chemokines and their receptors in malignancy. Front Immunol 11: 952, 2020.

110. Nazari A, Khorramdelazad H and Hassanshahi G: Biolog ical/pathological functions of the CXCL12/CXCR4/CXCR7 axes in the pathogenesis of bladder cancer. Int J Clin Oncol 22 991-1000, 2017.

111. Daniel SK, Seo YD and Pillarisetty VG: The CXCL12CXCR4/CXCR7 axis as a mechanism of immune resistance in gastrointestinal malignancies. Semin Cancer Biol 65:176-188: 2020.

112. Cabrero-de Las Heras S and Martínez-Balibrea E: CXC family of chemokines as prognostic or predictive biomarkers and possible drug targets in colorectal cancer. World J Gastroenterol 24 4738-4749, 2018.

113. Krikun G: The CXL12/CXCR4/CXCR7 axis in female reproductive tract disease: Review. Am J Reprod Immunol 80 e13028, 2018.

114. Cheng X, Wang H, Zhang X, Zhao S, Zhou Z, Mu X, Zhao C and Teng W: The role of SDF-1/CXCR4/CXCR7 in neuronal regeneration after cerebral ischemia. Front Neurosci 11: 590, 2017.

115. Al-Toub M, Almohawes M, Vishnubalaji R, Alfayez M, Aldahmash A, Kassem M and Alajez NM: CXCR7 signaling promotes breast cancer survival in response to mesenchymal stromal stem cell-derived factors. Cell Death Discov 5: 87, 2019.

116. Floranović MP and Veličković LJ: Effect of CXCL12 and its receptors on unpredictable renal cell carcinoma. Clin Genitourin Cancer 18: e337-e342, 2020.

117. Winer A, Adams S and Mignatti P: Matrix metalloproteinase inhibitors in cancer therapy: turning past failures into future successes. Mol Cancer Ther 17: 1147-1155, 2018

118. Cui N, Hu M and Khalil RA: Biochemical and biological attributes of matrix metalloproteinases. Prog Mol Biol Transl Sci 147: 1-73, 2017.

119. Parks WC, Wilson CL and López-Boado YS: Matrix metalloproteinases as modulators of inflammation and innate immunity. Nat Rev Immunol 4: 617-629, 2004.

120. Fingleton B: Matrix metalloproteinases as regulators of inflammatory processes. Biochim Biophys Acta Mol Cell Res 1864 2036-2042, 2017.

121. Peters F and Becker-Pauly C: Role of meprin metalloproteases in metastasis and tumor microenvironment. Cancer Metastasis Rev 38: 347-356, 2019.

122. Su CW, Lin CW, Yang WE and Yang SF: TIMP-3 as a therapeutic target for cancer. Ther Adv Med Oncol: Jul 16,2019 (Epub ahead of print). 1758835919864247, 2019. doi: 10.1177/1758835919864247.

123. Eckfeld C, Häußler D, Schoeps B, Hermann CD and Krüger A Functional disparities within the TIMP family in cancer: Hints from molecular divergence. Cancer Metastasis Rev 38: 469-481, 2019.

124. Gong D, Zhang J, Chen Y, Xu Y, Ma J, Hu G, Huang Y, Zheng J, Zhai $\mathrm{W}$ and Xue W: The $\mathrm{m}^{6} \mathrm{~A}$-suppressed P2RX6 activation promotes renal cancer cells migration and invasion through ATP-induced $\mathrm{Ca}(2+)$ influx modulating ERK1/2 phosphorylation and MMP9 signaling pathway. J Exp Clin Cancer Res 38 233, 2019.

125. Niu H, Li F, Wang Q, Ye Z, Chen Q and Lin Y: High expression level of MMP9 is associated with poor prognosis in patients with clear cell renal carcinoma. PeerJ 6: e5050, 2018.

126. Gonzalez-Molina J, Gramolelli S, Liao Z, Carlson JW, Ojala PM and Lehti K: MMP14 in sarcoma: A regulator of tumor microenvironment communication in connective tissues. Cells 8: 991, 2019.

127. Gifford V and Itoh Y: MT1-MMP-dependent cell migration: Proteolytic and non-proteolytic mechanisms. Biochem Soc Trans 47: 811-826, 2019. 
128. Cepeda MA, Evered CL, Pelling JJH and Damjanovski S: Inhibition of MT1-MMP proteolytic function and ERK1/2 signalling influences cell migration and invasion through changes in MMP-2 and MMP-9 levels. J Cell Commun Signal 11: 167-179, 2017.

129. Petrella BL and Brinckerhoff CE: Tumor cell invasion of von Hippel Lindau renal cell carcinoma cells is mediated by membrane type-1 matrix metalloproteinase. Mol Cancer 5: 66, 2006

130. Jiang B, Liu J and Lee MH: Targeting a designer TIMP-1 to the cell surface for effective MT1-MMP inhibition: A potential role for the prion protein in renal carcinoma therapy. Molecules 24 255, 2019.

131. Wu G, Ma Z, Cheng Y, Hu W, Deng C, Jiang S, Li T, Chen F and Yang Y: Targeting Gas6/TAM in cancer cells and tumor microenvironment. Mol Cancer 17: 20, 2018

132. Kovaleva OV, Samoilova DV, Shitova MS and Gratchev A Tumor associated macrophages in kidney cancer. Anal Cell Pathol (Amst) 2016: 9307549, 2016

133. Santoni M, Massari F, Amantini C, Nabissi M, Maines F Burattini L, Berardi R, Santoni G, Montironi R, Tortora G and Cascinu S: Emerging role of tumor-associated macrophages as therapeutic targets in patients with metastatic renal cell carcinoma. Cancer Immunol Immunother 62: 1757-1768, 2013.

134. Toge $\mathrm{H}$, Inagaki $\mathrm{T}$, Kojimoto $\mathrm{Y}$, Shinka $\mathrm{T}$ and Hara $\mathrm{I}$ : Angiogenesis in renal cell carcinoma: The role of tumor-associated macrophages. Int J Urol 16: 801-807, 2009.

135. Fu Q, Xu L, Wang Y, Jiang Q, Liu Z, Zhang J, Zhou Q, Zeng H, Tong S, Wang T, et al: Tumor-associated macrophage-derived interleukin-23 interlinks kidney cancer glutamine addiction with immune evasion. Eur Urol 75: 752-763, 2019.

136. Tcyganov E, Mastio J, Chen E and Gabrilovich DI: Plasticity of myeloid-derived suppressor cells in cancer. Curr Opin Immunol 51: 76-82, 2018.

137. Sun L, Clavijo PE, Robbins Y, Patel P, Friedman J, Greene S, Das R, Silvin C, Van Waes C, Horn LA, et al: Inhibiting myeloid-derived suppressor cell trafficking enhances $\mathrm{T}$ cell immunotherapy. JCI Insight 4: e126853, 2019.

138. Zhang J, Shi Z, Xu X, Yu Z and Mi J: The influence of microenvironment on tumor immunotherapy. FEBS J 286: 4160-4175, 2019

139. Martinez M and Moon EK: CAR T cells for solid tumors: New strategies for finding, infiltrating, and surviving in the tumor microenvironment. Front Immunol 10: 128, 2019.

140. Fleming V, Hu X, Weber R, Nagibin V, Groth C, Altevogt P, Utikal J and Umansky V: targeting myeloid-derived suppressor cells to bypass tumor-induced immunosuppression. Front Immunol 9: 398, 2018

141. Hinshaw DC and Shevde LA: The tumor microenvironment innately modulates cancer progression. Cancer Res 79 4557-4566, 2019.

142. Marvel D and Gabrilovich DI: Myeloid-derived suppressor cells in the tumor microenvironment: Expect the unexpected. J Clin Invest 125: 3356-3364, 2015

143. Najjar YG, Rayman P, Jia X, Pavicic PG Jr, Rini BI, Tannenbaum C, Ko J, Haywood S, Cohen P, Hamilton T, et al: Myeloid-derived suppressor cell subset accumulation in renal cell carcinoma parenchyma is associated with intratumoral expression of IL1 $\beta$, IL8, CXCL5, and Mip-1 $\alpha$. Clin Cancer Res 23: 2346-2355, 2017.

144. Kondo T, Nakazawa H, Ito F, Hashimoto Y, Osaka Y, Futatsuyama $\mathrm{K}$, Toma $\mathrm{H}$ and Tanabe $\mathrm{K}$ : Favorable prognosis of renal cell carcinoma with increased expression of chemokines associated with a Th1-type immune response. Cancer Sci 97 780-786, 2006.

145. Jöhrer K, Zelle-Rieser C, Perathoner A, Moser P, Hager M, Ramoner R, Gander H, Höltl L, Bartsch G, Greil R and Thurnher M: Up-regulation of functional chemokine receptor CCR3 in human renal cell carcinoma. Clin Cancer Res 11: 2459-2465, 2005

146. Yang JF, Shi SN, Xu WH, Qiu YH, Zheng JZ, Yu K, Song XY, Li F, Wang Y, Wang R, et al: Screening, identification and validation of CCND1 and PECAM1/CD31 for predicting prognosis in renal cell carcinoma patients. Aging (Albany NY) 11 12057-12079, 2019

147. Wang C, Wang Y, Hong T, Cheng B, Gan S, Chen L, Zhang J, Zuo L, Li J and Cui X: Blocking the autocrine regulatory loop of Gankyrin/STAT3/CCL24/CCR3 impairs the progression and pazopanib resistance of clear cell renal cell carcinoma. Cell Death Dis 11: 117, 2020
148. Kallakury BV, Karikehalli S, Haholu A, Sheehan CE, Azumi N and Ross JS: Increased expression of matrix metalloproteinases 2 and 9 and tissue inhibitors of metalloproteinases 1 and 2 correlate with poor prognostic variables in renal cell carcinoma. Clin Cancer Res 7: 3113-3119, 2001.

149. Woschek M, Kneip N, Jurida K, Marzi I and Relja B: Simvastatin reduces cancerogenic potential of renal cancer cells via geranylgeranyl pyrophosphate and mevalonate pathway. Nutr Cancer 68: 420-427, 2016.

150. Pang X, Si J, Xu S, Li Y and Liu J: Simvastatin inhibits homocysteine-induced CRP generation via interfering with the ROS-p38/ERK1/2 signal pathway in rat vascular smooth muscle cells. Vascul Pharmacol 88: 42-47, 2017.

151. Fang Z, Tang Y, Fang J, Zhou Z, Xing Z, Guo Z, Guo X, Wang W, Jiao W, Xu Z and Liu Z: Simvastatin inhibits renal cancer cell growth and metastasis via AKT/mTOR, ERK and JAK2/STAT3 pathway. PLoS One 8: e62823, 2013.

152. Ni X, Hu G and Cai X: The success and the challenge of all-trans retinoic acid in the treatment of cancer. Crit Rev Food Sci Nutr 59 (Sup 1): S71-S80, 2019.

153. Schultze E, Collares T, Lucas CG and Seixas FK: Synergistic and additive effects of ATRA in combination with different anti-tumor compounds. Chem Biol Interact 285: 69-75, 2018

154. Ren M, Pozzi S, Bistulfi G, Somenzi G, Rossetti S and Sacchi N: Impaired retinoic acid (RA) signal leads to RARbeta 2 epigenetic silencing and RA resistance. Mol Cell Biol 25: 10591-10603, 2005.

155. Chu JH, Gao ZH and Qu XJ: Down-regulation of sphingosine kinase 2 (SphK2) increases the effects of all-trans-retinoic acid (ATRA) on colon cancer cells. Biomed Pharmacother 68: 1089-1097, 2014.

156. Zarrabi K and Wu S: An evaluation of nivolumab for the treatment of metastatic renal cell carcinoma. Expert Opin Biol Ther 18: 695-705, 2018.

157. Zhang J, Dang F, Ren J and Wei W: Biochemical aspects of PD-L1 regulation in cancer immunotherapy. Trends Biochem Sci 43: 1014-1032, 2018.

158. Shi Y: Regulatory mechanisms of PD-L1 expression in cancer cells. Cancer Immunol Immunother 67: 1481-1489, 2018.

159. Ai L, Xu A and Xu J: Roles of PD-1/PD-L1 pathway: Signaling, cancer, and beyond. Adv Exp Med Biol 1248: 33-59, 2020.

160. Motzer RJ, Tannir NM, McDermott DF, Arén Frontera O, Melichar B, Choueiri TK, Plimack ER, Barthélémy P, Porta C, George S, et al: Nivolumab plus ipilimumab versus sunitinib in advanced renal-cell carcinoma. N Engl J Med 378: 1277-1290, 2018.

161. Chambers CA, Kuhns MS, Egen JG and Allison JP: CTLA-4-mediated inhibition in regulation of T cell responses: Mechanisms and manipulation in tumor immunotherapy. Annu Rev Immunol 19: 565-594, 2001.

162. Izzedine H, Mateus C, Boutros C, Robert C, Rouvier P, Amoura $Z$ and Mathian A: Renal effects of immune checkpoint inhibitors. Nephrol Dial Transplant 32: 936-942, 2017.

163. Rotte A: Combination of CTLA-4 and PD-1 blockers for treatment of cancer. J Exp Clin Cancer Res 38: 255, 2019.

164. Motzer RJ, Rini BI, McDermott DF, Arén Frontera O, Hammers HJ, Carducci MA, Salman P, Escudier B, Beuselinck B, Amin A, et al: Nivolumab plus ipilimumab versus sunitinib in first-line treatment for advanced renal cell carcinoma: Extended follow-up of efficacy and safety results from a randomised, controlled, phase 3 trial. Lancet Oncol 20: 1370-1385, 2019.

165. Wculek SK, Cueto FJ, Mujal AM, Melero I, Krummel MF and Sancho D: Dendritic cells in cancer immunology and immunotherapy. Nat Rev Immunol 20: 7-24, 2020.

166. Curiel TJ, Wei S, Dong H, Alvarez X, Cheng P, Mottram P, Krzysiek R, Knutson KL, Daniel B, Zimmermann MC, et al: Blockade of B7-H1 improves myeloid dendritic cell-mediated antitumor immunity. Nat Med 9: 562-567, 2003.

167. Gottfried E, Kunz-Schughart LA, Ebner S, Mueller-Klieser W, Hoves S, Andreesen R, Mackensen A and Kreutz M Tumor-derived lactic acid modulates dendritic cell activation and antigen expression. Blood 107: 2013-2021, 2006.

168. Delamarre L and Mellman I: Harnessing dendritic cells for immunotherapy. Semin Immunol 23: 2-11, 2011.

169. Farhood B, Najafi M and Mortezaee K: CD8(+) cytotoxic $\mathrm{T}$ lymphocytes in cancer immunotherapy: A review. J Cell Physiol 234: 8509-8521, 2019.

170. Boissonnas A, Fetler L, Zeelenberg IS, Hugues S and Amigorena S: In vivo imaging of cytotoxic T cell infiltration and elimination of a solid tumor. J Exp Med 204: 345-356, 2007. 
171. Dyck L and Mills KHG: Immune checkpoints and their inhibition in cancer and infectious diseases. Eur J Immunol 47: 765-779, 2017.

172. Motz GT and Coukos G: Deciphering and reversing tumor immune suppression. Immunity 39: 61-73, 2013.

173. Zitvogel L, Galluzzi L, Smyth MJ and Kroemer G: Mechanism of action of conventional and targeted anticancer therapies: Reinstating immunosurveillance. Immunity 39: 74-88, 2013.

174. Palucka K and Banchereau J: Dendritic-cell-based therapeutic cancer vaccines. Immunity 39: 38-48, 2013.

175. Xu W, Atkins MB and McDermott DF: Checkpoint inhibitor immunotherapy in kidney cancer. Nat Rev Urol 17: 137-150, 2020.

176. Chen DS and Hurwitz H: Combinations of Bevacizumab with cancer immunotherapy. Cancer J 24: 193-204, 2018.

177. Motz GT, Santoro SP, Wang LP, Garrabrant T, Lastra RR, Hagemann IS, Lal P, Feldman MD, Benencia F and Coukos G: Tumor endothelium FasL establishes a selective immune barrier promoting tolerance in tumors. Nat Med 20: 607-615, 2014.

178. Kochenderfer JN and Rosenberg SA: Treating B-cell cancer with $\mathrm{T}$ cells expressing anti-CD19 chimeric antigen receptors Nat Rev Clin Oncol 10: 267-276, 2013

179. Khalil DN, Smith EL, Brentjens RJ and Wolchok JD: The future of cancer treatment: Immunomodulation, CARs and combination immunotherapy. Nat Rev Clin Oncol 13: 273-290, 2016.

180. Chen DS and Mellman I: Oncology meets immunology: The cancer-immunity cycle. Immunity 39: 1-10, 2013

181. Sourbier C, Lindner V, Lang H, Agouni A, Schordan E, Danilin S, Rothhut S, Jacqmin D, Helwig JJ and Massfelder T: The phosphoinositide 3-kinase/Akt pathway: A new target in human renal cell carcinoma therapy. Cancer Res 66: 5130-5142, 2006.

182. Daurkin I, Eruslanov E, Stoffs T, Perrin GQ, Algood C, Gilbert SM, Rosser CJ, Su LM, Vieweg J and Kusmartsev S: Tumor-associated macrophages mediate immunosuppression in the renal cancer microenvironment by activating the 15-lipoxygenase-2 pathway. Cancer Res 71: 6400-6409, 2011.

183. Shinko D, Diakos CI, Clarke SJ and Charles KA: Cancer-related systemic inflammation: The challenges and therapeutic opportunities for personalized medicine. Clin Pharmacol Ther 102: 599-610, 2017.

184. Struyf S, Proost P, Vandercappellen J, Dempe S, Noyens B, Nelissen S, Gouwy M, Locati M, Opdenakker G, Dinsart C and Van Damme J: Synergistic up-regulation of MCP-2/CCL8 activity is counteracted by chemokine cleavage, limiting its inflammatory and anti-tumoral effects. Eur J Immunol 39 843-857, 2009.
185. Iyengar NM, Gucalp A, Dannenberg AJ and Hudis CA: Obesity and cancer mechanisms: Tumor microenvironment and inflammation. J Clin Oncol 34: 4270-4276, 2016.

186. Voelkel-Johnson C: TRAIL-mediated signaling in prostate, bladder and renal cancer. Nat Rev Urol 8: 417-427, 2011.

187. Chen YS, Hung TW, Su SC, Lin CL, Yang SF, Lee CC, Yeh CF, Hsieh YH and Tsai JP: MTA2 as a potential biomarker and its involvement in metastatic progression of human renal cancer by miR-133b Targeting MMP-9. Cancers (Basel) 11: 1851, 2019.

188. De Giorgi U, Procopio G, Giannarelli D, Sabbatini R, Bearz A, Buti S, Basso U, Mitterer M, Ortega C, Bidoli $\mathrm{P}$, et al: Association of systemic inflammation index and body mass index with survival in patients with renal cell cancer treated with nivolumab. Clin Cancer Res 25: 3839-3846, 2019.

189. Qayyum T, McArdle PA, Lamb GW, Going JJ, Orange C, Seywright M, Horgan PG, Oades G, Aitchison MA and Edwards J: Prospective study of the role of inflammation in renal cancer. Urol Int 88: 277-281, 2012.

190. Wen L, Guo L, Zhang W, Li Y, Jiang W, Di X, Ma J, Feng L, Zhang $\mathrm{K}$ and Shou J: Cooperation between the inflammation and coagulation systems promotes the survival of circulating tumor cells in renal cell carcinoma patients. Front Oncol 9: 504, 2019.

191. Sun KH, Sun GH, Wu YC, Ko BJ, Hsu HT and Wu ST: TNF- $\alpha$ augments CXCR2 and CXCR3 to promote progression of renal cell carcinoma. J Cell Mol Med 20: 2020-2028, 2016.

192. Barata PC and Rini BI: Treatment of renal cell carcinoma: Current status and future directions. CA Cancer J Clin 67: 507-524, 2017.

This work is licensed under a Creative Commons Attribution-NonCommercial-NoDerivatives 4.0 International (CC BY-NC-ND 4.0) License. 